\title{
Study Protocol Version Target Anatomic Site Code
}

National Cancer Institute

\section{Source}

National Cancer Institute. Study Protocol Version Target Anatomic Site Code. NCI

Thesaurus. Code C94127.

A coded value specifying the anatomic location that is the focus of a study. 